Original Article

\title{
DEVELOPMENT AND VALIDATION OF UV-SPECTROPHOTOMETRIC METHOD FOR DETERMINATION OF CLENBUTEROL HYDROCHLORIDE IN BULK AND PHARMACEUTICAL FORMULATION
}

\author{
SUSHMITA KANKURE1 ${ }^{*}$, MALLINATH KALSHETTI' ${ }^{1}$, RAVIKANT PATIL ${ }^{1}$
}

1D. S. T. S. Mandal's College of Pharmacy, Solapur 413004, Maharashtra, India

Email: sushmita.kankure@gmail.com

Received: 20 Nov 2019, Revised and Accepted: 19 Jan 2020

\section{ABSTRACT}

Objective: The objective of the present work is to develop a simple, rapid, economic UV spectrophotometric method for quantification of clenbuterol hydrochloride in bulk and pharmaceutical formulation as per ICH guidelines.

Methods: A UV spectrophotometric method has been developed using water as solvent to determine the Clenbuterol hydrochloride in bulk and pharmaceutical dosage formulation. The $\lambda_{\max }$ of Clenbuterol hydrochloride in water was found to be $242 \mathrm{~nm}$.

Results: The drug was proved linear in the range of $10-50 \mu \mathrm{g} / \mathrm{ml}$ and exhibited good correlation coefficient $\left(\mathrm{R}^{2}=0.9987\right)$ and excellent mean recovery (98-100\%). The \%RSD for intra-day and inter-day precision was found to be 0.053997676 and 0.359081556 respectively. The LOD and LOQ of clenbuterol hydrochloride was found to be 3.704448 and 11.2256 respectively. This method was successfully applied to clenbuterol content in marketed brands and the results were in good agreement with the label claims.

Conclusion: The method was validated for linearity, precision, repeatability and reproducibility. The obtained results proved that the method can be employed for the routine analysis of clenbuterol in bulks as well as in commercial formulations.

Keywords: Clenbuterol hydrochloride, UV, Water, Method development, Validation

(C) 2020 The Authors. Published by Innovare Academic Sciences Pvt Ltd. This is an open access article under the CC BY license (http://creativecommons.org/licenses/by/4.0/) DOI: http://dx.doi.org/10.22159/ijcpr.2020v12i2.37503. Journal homepage: https://innovareacademics.in/journals/index.php/ijcpr

\section{INTRODUCTION}

Clenbuterol hydrochloride $\quad\left(\mathrm{C}_{12} \mathrm{H}_{19} \mathrm{Cl}_{3} \mathrm{~N}_{2} \mathrm{O}\right)$, 1-(4-amino-3,5dichlorophenyl)-2-(tert-butylamino)ethan-1-ol hydrochloride, is a hydrochloride that is the mono-hydrochloride salt of clenbuterol. It has a role as a bronchodilator agent, a beta-adrenergic agonist and a sympathomimetic agent [1]. Clenbuterol is a sympathomimetic amine used by sufferers of breathing disorders as a decongestant and bronchodilator. It is most commonly available as the hydrochloride salt, clenbuterol hydrochloride [2]. Amongthe various method available for the determination of drugs, spectrophotometry continues to be very popular, because of their simplicity, specificity and low cost. This study presents a new spectrophotometric method for the determination of clenbuterol hydrochloride in bulk and pharmaceutical formulations. It is effective in improving peak expiratory flow rate (PEFR) in asthma patients [3].Clenbuterol is also a performanceenhancing drug as it stimulates the central nervous system and improves oxygen transport. Clenbuterol elicits cardio protective functionality in patients with dilated cardiomyopathy [4].<smiles>CC(C)(C)NCC(O)c1cc(Cl)c(N)c(Cl)c1</smiles>

Fig. 1: Structure of clenbuterol hydrochloride

\section{MATERIALS AND METHODS}

\section{Materials}

Instrument used

A double beam UV-visible spectrophotometer (Shimatzu, model 1800) was used for recording of spectra and measuring absorbance.
An electronic analytical weighing balance (Shimadzu, AY 220) were used in this study.

\section{Chemicals used}

Clenbuterol hydrochloride pure drug was a gift sample from Vamsi Labs Ltd., Solapur. Distilled water is used as solvent.

\section{Methods}

Preparation of standard stock solution

Accurately weighed $10 \mathrm{mg}$ of clenbuterol hydrochloride was transferred to a $100 \mathrm{ml}$ volumetric flask, dissolved in $20 \mathrm{ml}$ of distilled water by shaking manually. The volume was adjusted with the same up to the mark to give the final strength $(100 \mu \mathrm{g} / \mathrm{ml})$.

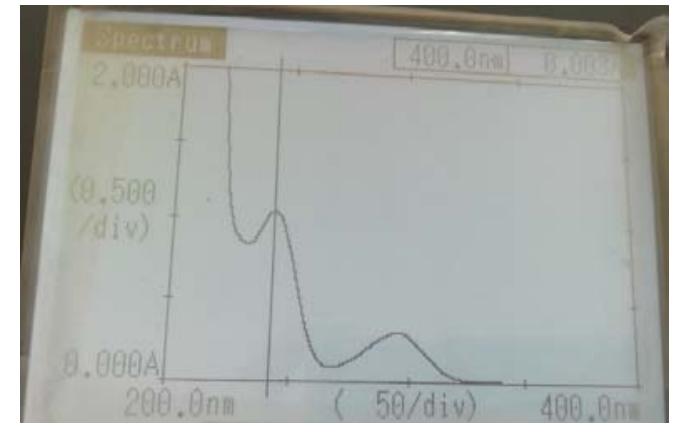

Fig. 2: UV spectrum of clenbuterol hydrochloride at $242 \mathrm{~nm}$

Selection of wavelength for analysis of clenbuterol hydrochloride

Appropriate volume $5 \mathrm{ml}$ of standard stock solution of clenbuterol hydrochloride was transferred into a $10 \mathrm{ml}$ of volumetric flask, 
diluted to a mark with distilled water to give concentration of $50 \mu \mathrm{g} / \mathrm{ml}$. The resulting solution was scanned in the UV range (200$400 \mathrm{~nm}$ ), clenbuterol hydrochloride showed absorbance maximum at $242 \mathrm{~nm}$ (fig. 2).

\section{Validation of the method}

The method was validated as per ICH guidelines in terms of linearity, accuracy, precision, sensitivity, ruggedness and robustness.

\section{Linearity}

Different aliquots of clenbuterol hydrochloride in the range 1-5 ml were transferred into series of $10 \mathrm{ml}$ volumetric flasks, and the volume was made upto the mark with distilled water to get concentrations $10,20,30,40$ and $50 \mu \mathrm{g} / \mathrm{ml}$, respectively. The solutions were analysedin the UV range on spectrophotometer. The spectrum was recorded at $242 \mathrm{~nm}$. The calibration plot was plotted as absorbance vs. concentration.

Table 1: Linearity of clenbuterol hydrochloride

\begin{tabular}{lll}
\hline S. No. & Concentration $(\mu \mathrm{g} / \mathbf{m l})$ & Absorbance \\
\hline 1 & 10 & 0.364 \\
2 & 20 & 0.68 \\
3 & 30 & 0.956 \\
4 & 40 & 1.317 \\
5
\end{tabular}

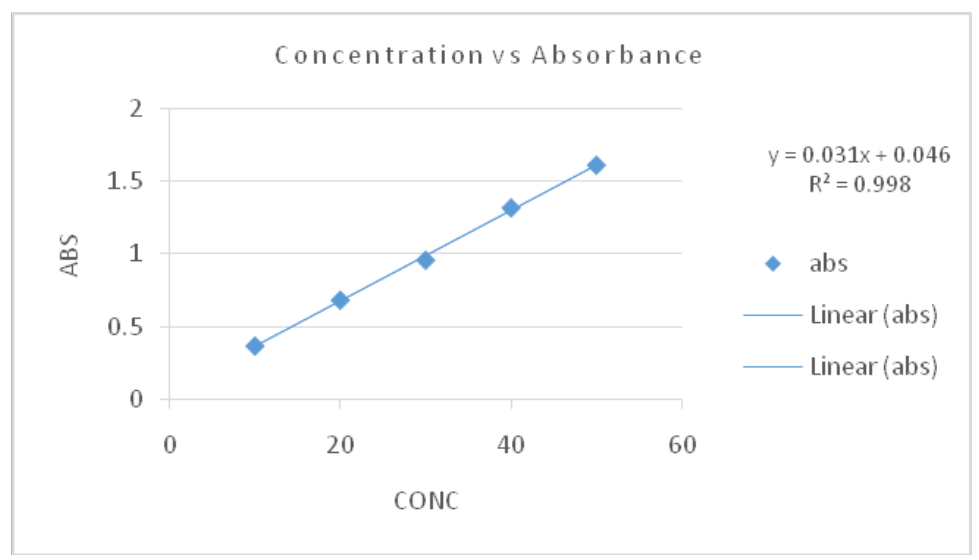

Fig. 3: Calibration curve of clenbuterol hydrochloride

Table 2: Recovery studies

\begin{tabular}{llll}
\hline $\begin{array}{l}\text { Concentration } \\
(\boldsymbol{\mu g} / \mathbf{m l})\end{array}$ & $\begin{array}{l}\text { \% of standard spiked to } \\
\text { sample }\end{array}$ & $\begin{array}{l}\text { Total including spiked sample } \\
(\boldsymbol{\mu g} / \mathbf{m l})\end{array}$ & $\begin{array}{l}\text { Spiked sample determined } \\
(\boldsymbol{\mu} \mathbf{g} / \mathbf{m l})\end{array}$ \\
\hline 100 & 80 & 16 & $\begin{array}{l}\text { \% of drug } \\
\text { recovered }\end{array}$ \\
100 & 100 & 20 & 15.81 \\
100 & 120 & 24 & 23.74 \\
\hline
\end{tabular}

Table 3: Precision studies

\begin{tabular}{llll}
\hline S. No. & Concentration $(\boldsymbol{\mu g} / \mathbf{m l})$ & Intra-day precision & Inter-day precision \\
\hline 1 & 30 & 0.956 & 0.931 \\
2 & 30 & 0.957 & 0.933 \\
3 & 30 & 0.957 & 0.926 \\
4 & 30 & 0.956 & 0.935 \\
5 & 30 & 0.956 & 0.932 \\
6 & 30 & 0.956 & 0.935 \\
& Average & 0.956333333 & 0.932 \\
& Standard deviation & 0.000516398 & 0.00334664 \\
& \% RSD & 0.053997676 & 0.359081556 \\
\hline
\end{tabular}

\section{Accuracy}

To the preanalyzed sample solutions, a known amount of standard stock solution was added at different levels, i.e. $80 \%$, $100 \%$ and $120 \%$. The solutions were reanalysed by the proposed method.

\section{Precision}

Precision of the method is studied as intra-day precision and interday precision. Intra-day precision was determined by analysing the solution of known concentration i.e. $30 \mu \mathrm{g} / \mathrm{ml}$ six times in the day. Inter-day precision was determined by analysing the same solution for $3 \mathrm{~d}$ over period of week. The \%RSD was found to be 0.053997676 and 0.359081556 respectively. The \%RSD values found to be less than 2 .

\section{Sensitivity}

The sensitivity of clenbuterol hydrochloride by proposed method was estimated by limit of detection (LOD) and limit of quantitation (LOQ). The LOD and LOQ were calculated using following formula-

$$
\mathrm{LOD}=3.3 \times \sigma / \mathrm{S}
$$$$
\mathrm{LOQ}=10 \times \sigma / \mathrm{S}
$$ 
Where ' $\sigma$ ' is standard deviation of the response and ' $S$ ' is the slope of the corresponding calibration curve of analyte.

The linearity equation was found to be $y=0.0313 x+0.0463$. The LOD and LOQ of clenbuterol hydrochloride was found to be 3.704448 and 11.2256 respectively.

\section{Robustness}

Robustness of the proposed method is determined for $10 \mu \mathrm{g} / \mathrm{ml}$ concentration of clenbuterol hydrochloride by analysis of aliquots from a homogenous slot for two different wavelengths, at two different temperature using same environmental conditions.

Table 4: Robustness studies

\begin{tabular}{llll}
\hline S. No. & Concentration $(\mu \mathrm{g} / \mathbf{m l})$ & Wavelength & Absorbance \\
\hline 1 & 10 & 241 & 0.284 \\
2 & 10 & 243 & 0.290 \\
\hline
\end{tabular}

Table 5: Ruggedness studies

\begin{tabular}{llll}
\hline S. No. & Concentration $(\boldsymbol{\mu g} / \mathbf{m l})$ & Absorbance (analyst 1) & Absorbance (Analyst 2) \\
\hline 1 & 10 & 0.294 & 0.293 \\
2 & 10 & 0.290 & 0.295 \\
3 & 10 & 0.297 & 0.291 \\
4 & 10 & 0.289 & 0.290 \\
5 & 10 & 0.292 & 0.295 \\
6 & 10 & 0.295 & 0.287 \\
\hline
\end{tabular}

\section{Ruggedness}

Ruggedness of the proposed method is determined by analysis of aliquots from a homogenous slot by two analysts for $10 \mu \mathrm{g} / \mathrm{ml}$ concentration of clenbuterol hydrochloride using same operational and environmental conditions.

\section{RESULTS AND DISCUSSION}

A validated simple, rapid, sensitive and accurate UV spectrophotometric method was developed for determination of clenbuterol hydrochloride in bulk and pharmaceutical formulation. Clenbuterol hydrochloride shows maximum absorbance at $242 \mathrm{~nm}$ in water. The clenbuterol hydrochloride follows Beer's Lambert's law in the linearity range of $10-50 \mu \mathrm{g} / \mathrm{ml}$. The linear regression of coefficient was found to be 0.9987 with equation $y=0.0313 x+0.0463$. Accuracy of drug was performed by recovery studies and it is near $100 \%$ i.e. 98 $100 \%$. The $\%$ recovery studies indicated that there is no interferents from the excipients present in the formulation. The LOD and LOQ was found to be 3.704448 and 11.2256 respectively.

\section{CONCLUSION}

The developed UV-spectrophotometric technique for quantification of clenbuterol hydrochloride in pharmaceutical formulation is quite simple, accurate, precise, reproducible and sensitive. The validation confirms that this is an appropriate method for their quantification in the different dosage form. It is also used in the routine quality control of the formulations containing this compound.

\section{ACKNOWLEDGMENT}

The authors are thankful to the Principal and Management, D. S. T. S. Mandal's College of Pharmacy, Solapur, Maharashtra, India for providing required facilities to carry out this research work.

\section{FUNDING}

Nil

\section{AUTHORS CONTRIBUTIONS}

All the authors have contributed equally.

\section{CONFLICT OF INTERESTS}

Declare none

\section{REFERENCES}

1. https://pubchem.ncbi.nlm.nih.gov/compound/Clenbuterolhydrochloride [Last accessed on 05 Oct 2019].

2. www.inchem/whofoodadditivesseries38/org. [Last accessed on 05 Oct 2019].

3. Anderson G, Wilkins E. A trial of clenbuterol in bronchial asthma. Thorax 1977;32:717-9.

4. Zhang Q, Xiang J, Wang X, Liu H, Hu B, Feng M, et al. Beta2adrenoceptor agonist clenbuterol reduces infarct size and myocardial apoptosis after myocardial ischaemia/ reperfusion in anaesthetized rats. $\mathrm{Br} J$ Pharmacol 2010;160:1561-72.

5. Yalcin Ozkan, Sibel A Ozkan, Hassan Y Aboul-Enein. Determination of clenbuterol $\mathrm{HCl}$ in human serum, pharmaceuticals and in drug dissolution studies by RPHPLC. J Liq Chromatogr Relat Technol 2001;24:679-91.

6. ICH Guidelines Q2 (R1). Validation of analytical procedures: text and methodology. In: ICH Harmonized Tripartite Guidelines; 2005. 